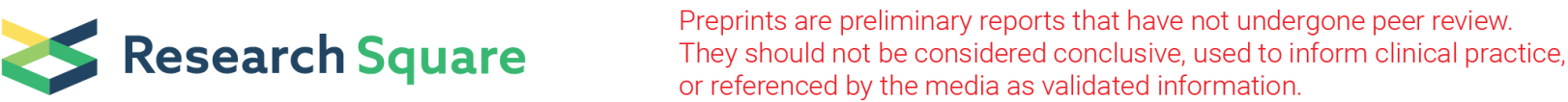

\section{Global 11 beta-hydroxysteroid dehydrogenase activity assessed by the circulating cortisol to cortisone ratio is associated with features of metabolic syndrome}

\section{La-or Chailurkit}

Ramathibodi Hospital https://orcid.org/0000-0002-1603-979X

Wichai Aekplakorn

Ramathibodi Hospital

Nitchawat Paiyabhroma

Ramathibodi Hospital

Boonsong Ongphiphadhanakul ( $\sim$ boonsong.ong@mahidol.ac.th )

https://orcid.org/0000-0002-3558-1621

Research article

Keywords: Cortisol, cortisone, 11 beta-hydroxysteroid dehydrogenase

Posted Date: January 13th, 2020

DOl: https://doi.org/10.21203/rs.2.20662/v1

License: (c) (1) This work is licensed under a Creative Commons Attribution 4.0 International License.

Read Full License 


\section{Abstract}

Background 11 Beta-hydroxysteroid dehydrogenases (11HSD) are enzymes involved in the interconversion of cortisol and cortisone. There are two isoenzymes of 11HSD, 11HSD1 and 11HSD2. A causative role of $11 \mathrm{HSD}$, particularly $11 \mathrm{HSD} 1$, in metabolic syndrome is well established in experimental animals. However, its role in human metabolic syndrome is less clear. We examined the influence of global 11HSD activity on metabolic syndrome in the general population, using the circulating cortisol:cortisone ratio as an index of global 11HSD activity.

Methods A subsample of 269 sera randomly selected from the Thai National Health Examination Survey IV samples was analyzed for serum cortisol and cortisone levels by liquid chromatography-tandem mass spectrometry.

Results There was no association between serum cortisol and age. However, circulating cortisone was negatively correlated with age $(r=-0.12, p<0.001)$, and the serum cortisol:cortisone ratio was positively associated with age $(r=0.03, P<0.001)$. No association was found between serum cortisol:cortisone ratio and $\mathrm{BMI}$ or serum lipids. Multivariate analyses showed that the serum cortisol:cortisone ratio was associated with high blood pressure $(P<0.05)$ independent of age, $\mathrm{BMI}$ and sex. In subjects without hypertension, the serum cortisol to cortisone ratio was associated with mean systolic blood pressure after controlling for age, BMI and sex. The cortisol:cortisone ratio was not significantly different between subjects with and without diabetes. After excluding the 16 subjects with diabetes, it was found that the serum cortisol:cortisone ratio was positively associated with fasting plasma glucose independent of age, $\mathrm{BMl}$ and $\operatorname{sex}(\mathrm{P}<0.01)$.

Conclusions The global index of 11HSD activity, assessed by the circulating cortisol:cortisone ratio, was related to high blood pressure and fasting plasma glucose. Modulation of 11HSD may help treat hypertension and diabetes but probably not other features of metabolic syndrome.

\section{Background}

The 11-beta hydroxysteroid dehydrogenases (11HSD) are enzymes that play roles in the interconversion of cortisol and cortisone. There are two 11 HSD isoenzymes, 11HSD1 and 11HSD2. 11HSD1 activity is detected in adipose and hepatic tissues where it catalyzes the conversion of cortisol to cortisone and vice versa. In comparison, 11HSD2 is expressed mainly in the kidneys and it is responsible for inhibiting the mineralocorticoid effect of cortisol, which has an equal binding affinity for glucocorticoid and mineralocorticoid receptors. Inactivating mutations in the 11HSD2 gene, or the inhibition of 11HSD2 by agents such as licorice, result in excessive mineralocorticoid action and hypertension.

Metabolic syndrome shares many features with Cushing's syndrome. The pathogenetic mechanisms are multifactorial, including direct and indirect cortisol action on lipolysis, free fatty acid production and turnover, very-low-density lipoprotein synthesis and fatty accumulation in the liver. A role for 11HSD, particularly 11HSD1, in metabolic syndrome has been well established in experimental animal models. 
Overexpression of 11HSD1 in adipose tissue resulted in animals exhibiting features of metabolic syndrome [1]. Administration of a high fat diet to animals also resulted in metabolic syndrome, which could be prevented in a 11HSD1 knockout model [2]. The role of 11HSD1 in human metabolic syndrome is less clear. The activity of 11HSD1 in metabolic syndrome appears tissue specific, as it is reduced in the liver and increased in adipose tissue [3, 4]. Consequently, the global activity of 11HSD1 and its relationship to metabolic syndrome remains unclear. In the present study, we investigated the association of global 11HSD1 activity with metabolic syndrome in the general population, using the circulating cortisol:cortisone ratio as an index of 11HSD global activity.

\section{Methods}

\section{Study population}

This study used a subsample of 269 participants who were randomly selected, by computer-generated random numbers, from the Thai $4^{\text {th }}$ National Health Examination Survey (NHES IV), conducted from August 2008 to March 2009 by the National Health Examination Survey Office, Health Systems Research Institute, Thailand. Anthropometric data, such as body weight, height and blood pressure, were recorded using standard procedures. Weight of barefoot participants wearing light clothing was measured to the nearest $100 \mathrm{~g}$ using a calibrated digital scale (TANITA model HD316, Tanita Corporation, Tokyo, Japan). Height was measured to the nearest $0.1 \mathrm{~cm}$ using a stadiometer, as participants stood barefoot with their shoulders in a normal position. Body mass index (BMI) was calculated according to Quetelet's formula as body weight $(\mathrm{kg})$ divided by height squared $\left(\mathrm{m}^{2}\right)$.

\section{Blood pressure measurement}

Participants rested in a sitting position for at least $5 \mathrm{~min}$ before measurement. Blood pressure was standardized and defined as systolic (SBP) and diastolic blood pressure (DBP) in $\mathrm{mmHg}$. These values were measured using an automatic blood pressure monitoring device (Microlife model A100, Microlife AG, Widnau, Switzerland) with each participant's arm supported with an appropriate arm cuff at the level of the heart. Three blood pressure measurements were obtained from all participants and the mean readings of the second and third measurements were recorded and used for the present analysis. Hypertension was defined as mean SBP $\geq 140 \mathrm{mmHg}$ or DBP $\geq 90 \mathrm{mmHg}$, or use of antihypertensive medication during the past 2 weeks, without any occurrence of heart failure, myocardial infarction, or stroke in the past 6 months and other relevant chronic diseases.

\section{Biochemical measurement}


Venous blood samples were obtained from participants the morning after an overnight fast. Serum samples were collected and transferred to the central laboratory at the Faculty of Medicine, Ramathibodi Hospital, for analyzing triglyceride (TG), high-density lipoprotein cholesterol (HDL-C), and low-density lipoprotein cholesterol (LDL-C). TG was measured by enzymatic colorimetric methods, while HDL-C and LDL-C were analyzed by homogeneous methods on an automated biochemical analyzer (Dimension RxL; Dade Behring, USA). Serum cortisol and cortisone were analyzed by liquid chromatography-tandem mass spectrometry (LC-MS/MS) with an Agilent 1260 Infinity liquid chromatograph (Agilent Technologies, Waldbronn, Germany) coupled to a QTRAP ${ }^{\circledR} 5500$ tandem mass spectrometer (AB SCiex, Foster City, CA, USA) using a MassChrom ${ }^{\circledR}$ Steroids in Serum/Plasma reagent kit (Chromsystems, Munich, Germany).

\section{Statistical Analysis}

Data were expressed as mean \pm standard deviation (SD) for continuous variables, and frequency (percentage) for binary and categorical variables when appropriate. In univariate analysis, comparison of serum cortisol:cortisone ratios between normal blood pressure subjects and those with hypertension were analyzed using an independent $t$-test to compare mean values. Multivariate logistic regression analyses were conducted to evaluate the potential of associated factors with the presence of high blood pressure in diabetes. Multiple robust regression was used to assess the association of the cortisol:cortisone ratio with relevant continuous parameters. A P value less than 0.05 was considered statistically significant. All analyses were performed using Stata Statistical Software, Release 13 (StataCorp, College station, TX, USA).

\section{Results}

Clinical characteristics of the study population are detailed in Table 1. Table 2 shows the association between serum cortisol, cortisone and the cortisol to cortisone ratio and age. There was no association between serum cortisol and age. However, circulating cortisone was negatively correlated with age $(r=-$ $0.12, p<0.001)$, and the serum cortisol to cortisone ratio was positively associated with age $(r=0.03, P<$ 0.001). Age was associated with the serum cortisol:cortisone ratio after controlling for $\mathrm{BMI}$, sex and urbanization (Table 3). It is of note that BMI was not associated with the serum cortisol:cortisone ratio. For serum lipids, no significant association was found between the serum cortisol:cortisone ratio and total cholesterol $(r=0.06, P=0.31)$, LDL cholesterol $(r=0.03, P=0.62)$, HDL cholesterol $(r=-0.02, P=$ $0.78)$ or triglyceride $(r=0.08, P=0.21)$. 
Table 1

Clinical characteristic of the study population $(n=269)$

\section{Characteristics}

Age (years)

Male (\%)

Urban residence (\%)

$\operatorname{BMI}\left(\mathrm{kg} / \mathrm{m}^{2}\right)$

$\mathrm{SBP}(\mathrm{mmHg})$

DBP $(\mathrm{mmHg})$

Triglyceride $(\mathrm{mmol} / \mathrm{L})$

Cholesterol (mmol/L)

HDL-C (mmol/L)

LDL-C (mmol/L)

BMI, body mass index; SBP, systolic blood pressure; DBP, diastolic blood pressure; HDL-C, high-density lipoprotein cholesterol; LDL-C, low-density lipoprotein cholesterol.
Mean \pm SD or $\%$

$49.0 \pm 22.3$

54.3

46.5

$23.3 \pm 4.9$

$124.2 \pm 20.5$

$73.5 \pm 10.9$

$1.63 \pm 1.27$

$5.33 \pm 1.15$

$1.22 \pm 0.30$

$3.38 \pm 1.03$

Table 2

Association between serum cortisol, cortisone and the cortisol:cortisone ratio with age.

\begin{tabular}{|ll|}
\hline Variables & Age \\
\hline Serum cortisol & $r=-0.20$ \\
& $P=0.15$ \\
\hline Serum cortisone & $r=-0.12$ \\
& $P<0.001$ \\
\hline Serum cortisol to cortisone ratio & $r=0.03$ \\
& $P<0.001$ \\
\hline
\end{tabular}


Table 3

Multiple linear regression analysis showing the association of age, BMI, sex and urban residence with the serum cortisol to cortisone ratio.

\begin{tabular}{|c|c|c|c|}
\hline \multirow[t]{2}{*}{ Factor } & \multicolumn{3}{|l|}{ Serum cortisol:cortisone ratio } \\
\hline & Regression coefficient (beta) & $95 \% \mathrm{Cl}$ & $P$ value \\
\hline Age (years) & 0.028 & $0.017-0.040$ & $<0.001$ \\
\hline $\mathrm{BMI}\left(\mathrm{kg} / \mathrm{m}^{2}\right)$ & 0.010 & $-0.043-0.062$ & $=0.715$ \\
\hline Male & 0.558 & $0.044-1.071$ & $=0.033$ \\
\hline Urban & 0.249 & $-0.262-0.759$ & $=0.339$ \\
\hline
\end{tabular}

When the study subjects were stratified into those with and without hypertension, it was found that the serum cortisol:cortisone ratio was significantly higher in subjects with high blood pressure compared with normotensive subjects (Table 4). In multivariate logistic regression models, it was found that the serum cortisol:cortisone ratio was associated with high blood pressure independent of age, BMI and sex (Table 5). In subjects without hypertension, the serum cortisol:cortisone ratio was associated with mean SBP after controlling for age, BMI and sex (Table 6). No such association was found for mean DBP.

Table 4

Differences in the serum cortisol:cortisone ratio between subjects with and without hypertension

\begin{tabular}{|llll|}
\hline & Number & Serum cortisol:cortisone ratio (mean \pm SD) & P value \\
\hline Without hypertension & 197 & $5.88 \pm 2.14$ & $<0.001$ \\
With hypertension & 72 & $7.43 \pm 2.38$ & \\
\hline
\end{tabular}


Table 5

Association between the serum cortisol:cortisone ratio and other variables with high blood pressure.

\begin{tabular}{|llll|}
\hline \multirow{2}{*}{ Factor } & \multicolumn{2}{l|}{ Blood pressure } & \\
\cline { 2 - 4 } & Regression coefficient & $95 \% \mathrm{Cl}$ & P value \\
\hline Serum cortisol to cortisone ratio & 0.213 & $0.046-0.380$ & 0.012 \\
\hline Age (years) & 0.107 & $0.078-0.137$ & $<0.001$ \\
\hline Male & 0.566 & $-0.191-1.322$ & 0.143 \\
\hline Body mass index $\left(\mathrm{kg} / \mathrm{m}^{2}\right)$ & 0.245 & $0.153-0.338$ & $<0.001$ \\
\hline
\end{tabular}

Table 6

Mutivariate logistic regression according to predictive factors on mean systolic blood pressure.

\begin{tabular}{|llll|}
\hline \multirow{3}{*}{ Factor } & \multicolumn{2}{l|}{ Mean systolic blood pressure } & \\
\cline { 2 - 4 } & Regression coefficient (beta) & $95 \% \mathrm{Cl}$ & P value \\
\hline Serum cortisol:cortisone ratio & 0.986 & $0.249-1.722$ & $=0.009$ \\
\hline Age (years) & 0.171 & $0.090-0.252$ & $<0.001$ \\
\hline Male & 0.756 & $0.423-1.089$ & $<0.001$ \\
\hline Body mass index $\left(\mathrm{kg} / \mathrm{m}^{2}\right)$ & 5.572 & $2.381-8.764$ & $=0.001$ \\
\hline
\end{tabular}

Sixteen out of 269 subjects had diabetes, as defined by fasting plasma glucose $\geq 126 \mathrm{mg} / \mathrm{dL}$ or a history of current diabetes medications. The cortisol:cortisone ratio was not significantly different between subjects with and without diabetes (Table 7). After excluding the 16 subjects with diabetes, it was found that the serum cortisol:cortisone ratio was positively associated with fasting plasma glucose independent of age, BMl and sex (Table 8).

Table 7

Differences in the serum cortisol:cortisone ratio between subjects without and with diabetes.

\begin{tabular}{|llll|}
\hline & Number & $\begin{array}{l}\text { Serum cortisol:cortisone ratio } \\
\text { (mean } \pm \text { SD) }\end{array}$ & P value \\
\hline Without diabetes & 253 & $6.26 \pm 0.15$ & $=0.42$ \\
\hline With diabetes & 16 & $6.75 \pm 0.51$ & \\
\hline
\end{tabular}


Table 8

Mutivariate logistic regression according to predictive factors on fasting plasma glucose in subjects without diabetes.

\begin{tabular}{|llll|}
\hline \multirow{3}{*}{ Factor } & \multicolumn{2}{l|}{ Mean systolic blood pressure } & \\
\cline { 2 - 4 } & Regression coefficient (beta) & $95 \% \mathrm{Cl}$ & P value \\
\hline Serum cortisol:cortisone ratio & 0.84 & $0.23-1.43$ & $<0.01$ \\
\hline Age (years) & 0.11 & $0.05-0.18$ & $<0.001$ \\
\hline Male & 0.92 & $-1.81-3.65$ & 0.50 \\
\hline Body mass index $\left(\mathrm{kg} / \mathrm{m}^{2}\right)$ & 0.31 & $0.03-0.59$ & $<0.05$ \\
\hline
\end{tabular}

\section{Discussion}

In the present study, we found that the circulating cortisol:cortisone ratio significantly increased with advancing age, mainly because of a decrease in cortisone rather than an increase in cortisol. In line with previous studies, we did not find a change in serum cortisol with age, although a decrease in cortisol secretion has been reported $[5,6]$. In contrast, we found that serum cortisone sharply decreased with aging. The main mechanism underlying the decrease in serum cortisone with aging is not clear. Cortisone is mainly produced from cortisol by the activity of 11HSD. The action of $11 \mathrm{HSD} 2$ preferentially converts cortisol to cortisone, and a reduction in 11HSD2 activity with aging has been demonstrated in humans [7]. There is no evidence for altered gene expression or activity of renal 11ß-HSD2 in aging rats [8], however, the conversion of cortisol to cortisone by $11 \mathrm{HSD} 2$ is mainly an intrarenal process, so its contribution to circulating levels of cortisone is not clear. The increased cortisol:cortisone ratio is more likely to reflect the increased activity of 11HSD 1 with aging. In humans, 11ß-HSD 1 activity was present in skin as well as skeletal muscle tissues, and increased with age $[9,10]$.

Metabolic syndrome is a major risk factor for future development of type 2 diabetes and cardiovascular disease. The underlying basis for the clustering of related cardiovascular risk factors into metabolic syndrome is unclear. Insulin resistance has been proposed as the predominant factor, but the notion is not without dispute [11]. Visceral obesity has also been proposed as the central factor [12]. With regard to $11 \mathrm{HSD}$, it has been demonstrated that 11HSD is associated with metabolic syndrome, and 11HSD inhibitors have therapeutic potential for this syndrome [13, 14]. However, in the present study, we could not find a significant association between the cortisol:cortisone ratio and the presence of metabolic syndrome. Nevertheless, the cortisol:cortisone ratio was related to some characteristics of metabolic syndrome, including fasting plasma glucose and SBP. These findings suggest that 11HSD may not be the underlying basis of metabolic syndrome, but it may pathologically contribute to glucose homeostasis and blood pressure control. The alteration in 11HSD activity may increase the prevalence of metabolic syndrome through its influence on some, but not all, of the characteristics of metabolic syndrome. In fact, 
the designation of metabolic syndrome and its usefulness has been called into question, partly because of an unclear unifying causative factor for the syndrome [15].

In the present study, the associations between the cortisol:cortisone ratio and fasting plasma glucose, as well as mean systolic hypertension, were in line with the role of 11HSD in glucose and blood pressure control. Studies in humans have demonstrated elevated 11b-HSD1 activity in adipose tissue of obese men and women [16,17]. A clinical study of carbenoxolone effects in diabetic subjects suggested a causal effect of elevated 11bHSD1 activity involving reduced glucose production during hyperglucagonemia $[13,18]$. With regard to blood pressure, although it is well established that reduced activity of 11HSD2 (which converts cortisol to cortisone in the kidneys), can lead to a syndrome of apparent mineralocorticoid excess with high blood pressure and hypokalemia, the contribution of renalspecific 11HSD2 upon the circulating cortisol:cortisone ratio is probably limited. In contrast, an 11HSD1 inhibitor, MK-0916, improved both systolic and diastolic blood pressure in humans [14]. Considering these findings together, the circulating cortisol:cortisone ratio may represent a global reflection of $11 \mathrm{HSD}$ activity, mainly via 11HSD1, and offer the potential to identify subjects more likely to respond to 11HSD1 inhibitors for the treatment of hyperglycemia and high blood pressure.

One of the limitations of our study is that we measured cortisol and cortisone in blood rather than urine samples. Given the circadian variation of circulating glucocorticoids, it may be more valid to assess the status of 11 HSD by examining 24-hour urine samples. It is not clear how the 11HSD activity measured in serum samples would reflect the activity in 24-hour urine samples. Nevertheless, 24-hour urine collection is cumbersome and inadequate collection procedures may cause sampling error, and the serum cortisol:cortisone ratio has been utilized adequately for such purpose [19]. In addition, detailed assessments of glucose homeostasis and blood pressure control could not be practically performed in the current population-based cross-sectional study. Nevertheless, findings obtained from such a population may be more generalizable to populations at large.

\section{Conclusion}

The global index of 11HSD activity assessed by the circulating cortisol:cortisone ratio was associated with high blood pressure and fasting plasma glucose. Modulation of 11HSD may provide a therapeutic approach for hypertension and diabetes but probably not other features of metabolic syndrome.

\section{Declarations}

\section{Acknowledgments}

This work was supported by the National Research Council of Thailand. We would like to thank Chromsystems, Germany and Helana Thai Laboratories Co. Ltd., for providing the steroid reagent kit. 


\section{Author's contribution}

BO and WA conducted and designed the study. LC and NP carried out the experiments. BO and LC performed the data analyses and wrote the manuscript. BO and LC participated in writing the manuscript. All authors discussed the results and contributed to the final manuscript.

\section{Ethics approval and consent to participate}

All participants gave their written informed consent before participating in the study. The study was approved by the Committee on Human Rights Related to Research Involving Human Subjects, Faculty of Medicine, Ramathibodi Hospital, Mahidol University, and it conformed with the provisions of the Declaration of Helsinki (as revised in Fortaleza, Brazil, October 2013).

\section{Consent for publication}

Not applicable.

\section{Competing interests}

The authors have no conflict of interest and nothing to disclose.

\section{Data Availability}

The data that support the findings of this study are available on request from the corresponding author. The data are not publicly available due to privacy or ethical restrictions.

\section{References}

1.

Masuzaki H, Paterson J, Shinyama H, Morton NM, Mullins JJ, Seckl JR, Flier JS. A transgenic model of visceral obesity and the metabolic syndrome. Science. 2001;294(5549):2166-70.

2.

Morton NM, Paterson JM, Masuzaki H, Holmes MC, Staels B, Fievet C, Walker BR, Flier JS, Mullins JJ, Seckl JR. Novel adipose tissue-mediated resistance to diet-induced visceral obesity in 11 betahydroxysteroid dehydrogenase type 1-deficient mice. Diabetes. 2004;53(4):931-8.

3. 
Stewart PM, Boulton A, Kumar S, Clark PM, Shackleton CH. Cortisol metabolism in human obesity: impaired cortisone->cortisol conversion in subjects with central adiposity. J Clin Endocrinol Metab. 1999;84(3):1022-7.

4.

Desbriere R, Vuaroqueaux V, Achard V, Boullu-Ciocca S, Labuhn M, Dutour A, Grino M. 11 beta-

hydroxysteroid dehydrogenase type $1 \mathrm{mRNA}$ is increased in both visceral and subcutaneous adipose tissue of obese patients. Obesity (Silver Spring Md). 2006;14(5):794-8.

5 .

Veldhuis JD, Sharma A, Roelfsema F. Age-dependent and gender-dependent regulation of hypothalamicadrenocorticotropic-adrenal axis. Endocrinol Metab Clin North Am. 2013;42(2):201-25.

6.

Zaidi SK, Shen W-J, Azhar S. Impact of aging on steroid hormone biosynthesis and secretion. Open Longev Sci. 2012;6:1-30.

7.

Henschkowski J, Stuck AE, Frey BM, Gillmann G, Dick B, Frey FJ, Mohaupt MG. Age-dependent decrease in 11 beta-hydroxysteroid dehydrogenase type 2 (11 beta-HSD2) activity in hypertensive patients. Am J Hypertens. 2008;21(6):644-9.

8.

Audige A, Dick B, Frey BM, Frey FJ, Corman B, Vogt B. Glucocorticoids and 11 beta-hydroxysteroid dehydrogenase type 2 gene expression in the aging kidney. Eur J Clin Invest. 2002;32(6):411-20. 9 .

Tiganescu A, Walker EA, Hardy RS, Mayes AE, Stewart PM. Localization, age- and site-dependent expression, and regulation of 11 beta-hydroxysteroid dehydrogenase type 1 in skin. J Invest Dermatol. 2011;131(1):30-6.

10.

Hassan-Smith ZK, Morgan SA, Sherlock M, Hughes B, Taylor AE, Lavery GG, Tomlinson JW, Stewart PM. Gender-Specific Differences in Skeletal Muscle 11beta-HSD1 Expression Across Healthy Aging. J Clin Endocrinol Metab. 2015;100(7):2673-81.

11.

Reaven GM. Banting lecture 1988. Role of insulin resistance in human disease. Diabetes. 1988;37(12):1595-607.

12.

Lemieux I, Pascot A, Couillard C, Lamarche B, Tchernof A, Almeras N, Bergeron J, Gaudet D, Tremblay G, Prud'homme $D$, et al: Hypertriglyceridemic waist: $A$ marker of the atherogenic metabolic triad (hyperinsulinemia; hyperapolipoprotein B; small, dense LDL) in men? Circulation 2000, 102(2):179-184. 13.

Andrews RC, Rooyackers $\mathrm{O}$, Walker BR. Effects of the 11 beta-hydroxysteroid dehydrogenase inhibitor carbenoxolone on insulin sensitivity in men with type 2 diabetes. J Clin Endocrinol Metab. 2003;88(1):285-91.

14. 
Feig PU, Shah S, Hermanowski-Vosatka A, Plotkin D, Springer MS, Donahue S, Thach C, Klein EJ, Lai E, Kaufman KD. Effects of an 11 beta-hydroxysteroid dehydrogenase type 1 inhibitor, MK-0916, in patients with type 2 diabetes mellitus and metabolic syndrome. Diabetes Obes Metab. 2011;13(6):498-504. 15.

Kahn R, Buse J, Ferrannini E, Stern M. The metabolic syndrome: time for a critical appraisal: joint statement from the American Diabetes Association and the European Association for the Study of Diabetes. Diabetes Care. 2005;28(9):2289-304.

16.

Rask E, Walker BR, Soderberg S, Livingstone DE, Eliasson M, Johnson O, Andrew R, Olsson T. Tissuespecific changes in peripheral cortisol metabolism in obese women: increased adipose 11 betahydroxysteroid dehydrogenase type 1 activity. J Clin Endocrinol Metab. 2002;87(7):3330-6. 17.

Rask E, Olsson T, Soderberg S, Andrew R, Livingstone DE, Johnson O, Walker BR. Tissue-specific dysregulation of cortisol metabolism in human obesity. J Clin Endocrinol Metab. 2001;86(3):1418-21. 18.

Walker BR, Connacher AA, Lindsay RM, Webb DJ, Edwards CR. Carbenoxolone increases hepatic insulin sensitivity in man: a novel role for 11-oxosteroid reductase in enhancing glucocorticoid receptor activation. J Clin Endocrinol Metab. 1995;80(11):3155-9.

19.

Jayasuriya NA, Hughes AE, Sovio U, Cook E, Charnock-Jones DS, Smith GCS. A Lower Maternal Cortisolto-Cortisone Ratio Precedes Clinical Diagnosis of Preterm and Term Preeclampsia by Many Weeks. J Clin Endocrinol Metab. 2019;104(6):2355-66. 